\title{
Investigating Phragmites Australis Response to Copper Exposure Using Physiologic囚FTIR and Metabolomic Approaches
}

Jieting Wu ( $\sim$ laurelwutougao@163.com )

School of Environment Science,Liaoning University,Shenyang,People's Republic of China

Tian Gao

School of Environment Science,Liaoning University,Shenyang,People's Republic of China

Fang Ma

Harbin Institute of Technology

Lei Zhao

Harbin Institute of Technology

\section{Research Article}

Keywords: Plant resistance, Metabolomics, FTIR, Arginine, Ayarin, Phragmites australis

Posted Date: June 22nd, 2021

DOl: https://doi.org/10.21203/rs.3.rs-633138/v1

License: (c) (i) This work is licensed under a Creative Commons Attribution 4.0 International License.

Read Full License 


\section{Abstract}

Background and aim Phragmites australis is a landscape plant with phytoremediation functions that is widely planted worldwide. However, little is known about the metabolomic background of the resistance mechanisms of Phragmites to heavy metals during its growth and development.

Methods Here, we performed copper stress studies on Phragmites and monitored physiological indicators such as malondialdehyde (MDA) and electrolyte leakage (EL). In addition, FTIR was used to study chemical composition changes in the roots, stems and leaves of Phragmites seedlings under excessive copper stress. Furthermore, LC-MS technology combined with metabolomics data processing software was used to analyze the metabolic profile of samples.

Result Copper contributed to the accumulation of MDA and EL. And the results of FTIR showed that the antioxidant effects of flavonoids and amino acids can be used by Phragmites leaf tissue to improve the tolerance of copper under $5 \mathrm{mg} / \mathrm{L}$ concentration. Further, the results of metabolomics reflected that Phragmites can improve its resistance to copper by increasing the accumulation of arginine and ayarin in the body. The former is accumulated through two pathways: the citrulline decomposition and conversion pathway and the circular pathway composed of ornithine, citrulline, L-Argininosuccinate and arginine. The latter is synthesized through the quercetin methylation pathway.

Conclusion This study provides insights into the resistance mechanism and repair performance of Phragmites and other plant accumulators in response to copper stress.

\section{Introduction}

Although copper is an essential trace element in plants, excessive copper is toxic to plants (Ugulu et al. 2012, Sahin 2016). Recently, copper pollution has attracted increasing attention due copper excessive emissions which are caused by different human activities such as mining, metal processing, fertilizer industry, fungicides, industrial and domestic wastewater and traffic discharges (Dogan,Baslar and Ugulu 2014, Unver et al. 2015, Ugulu,Unver and Dogan 2016). Excessive copper affects various physiological processes of plants, leading to abnormal growth and development (Ugulu 2015, Khan et al. 2019), and causes oxidative damage to cells by stimulating oxidative stress (Pisoschi and Pop 2015, Kapoor et al. 2019). Copper stress can stimulate a variety of defense mechanisms in plants such as antioxidant systems and antioxidants to control copper homeostasis (Yadav et al. 2018, Liu et al. 2019, Nazir,Hussain and Fariduddin 2019). Some metabolites (such as amino acids and flavonoids) have antioxidant effects in plants (Kovacik et al. 2010, Agati et al. 2020). Studying the changes of these metabolites and related metabolic pathways will help to reveal the intrinsic resistance mechanism of plants under heavy metal stress.

Generally, plant tolerance is a complex process that involves physiological, biochemical, and molecular changes, all of which being metabolic adjustments needed to adapt to environmental stresses to maintain plant growth (Lin and Aarts 2012, Farooq et al. 2016). By analyzing changes in metabolites, we 
can assess the organism's reaction to envionemental stresses (Hong et al. 2016). Studies show that metabolites themselves can act as modulators, which can enhance the signal transduction necessary for plants to quickly trigger tolerance mechanisms under stressful conditions (Hou,Ufer and Bartels 2016). In addition, metabolites can also play a direct role as final products to alleviate the harmful effects of various environmental pressures (Villiers et al. 2011). For example, metabolites can play an antioxidant role to respond to stress conditions (Arbona et al. 2013). Plants can also generate primary and secondary metabolites through a variety of complex metabolic pathways (Dixon and Strack 2003). Among them, primary metabolites such as sugars, amino acids, and lipids can provide necessary energy and molecules that are essential for growth and development. Therefore, the metabolic status of plants during growth can be known by monitoring the change of primary metabolites (Zhao et al. 2018). In addition, plants can produce a large number of secondary metabolites, such as flavonoids, terpenoids and glucosinolates, which can provide resistance to biotic and abiotic stressors (Keurentjes 2009). For instance, rice can produce many kinds of metabolites such as phenols, flavonols, carotenoids, and alkaloids under abiotic stresses (Kusano et al. 2015). Meanwhile, high Ni concentration has been shown to cause the roots of Matricaria chamomilla to produce oxidative stress responses, which stimulates the gradual accumulation of soluble phenols and flavonoids to resist oxidative damage (Kovacik,Klejdus and Backor 2009).

As one of the most common and widely distributed underground stem plants in the world, Phragmites has a strong viability and can survive and reproduce in the form of expanded rhizomes with buds (Wu et al. 2019). Phragmites has a strong environmental tolerance to resist heavy metals and other pollutants and has been widely used in the pollution remediation of wetlands (Wu et al. 2013, Ye et al. 2003). In addition, it is believed that Phragmites has strong heavy metal removal capabilities due to features such as rapid growth to form dense vegetation, higher above-ground biomass, typical tissue systems and defense mechanisms in the body, and higher bioaccumulation and heavy metal removal efficiency than other repair plants (Carricondo et al. 2020, Samaras,Sicilia and Garcia-Barriocanal 2021, Huang et al. 2018, Bonanno 2013).

In this study, we preliminarily assess the degree of plant damage in Phragmites under copper stress during growth and development by measuring the growth index, malondialdehyde (MDA), electrolyte leakage (EL), and copper concentration. Then, we further characterize the functional groups in Phragmites that have changed under copper stress by analyzing infrared data. Finally, we explore the mechanism of the molecular biological changes of internal metabolites of Phragmites leaves under copper stress using the results of LC-MS non-targeted metabolome analysis. The main goal of this study is to analyze the response mechanism of Phragmites to copper stress through metabolomics and further understand the tolerance and resistance mechanism of Phragmites.

\section{Materials And Methods}

Experimental Design and Growth Parameters 
P.australis seedlings used in the experiment were first hydrocultured for 20 days in pots containing $2 \mathrm{~L}$ of Hoagland nutrient solution, before being subjected to copper stress. $0.02 \mathrm{mg} \cdot \mathrm{l}^{-1}$ nutrient solution acted as the control group and the copper concentration gradient was set to 5,10 , and $20 \mathrm{mg} \cdot \mathrm{l}^{-1}$. Each treatment was repeated three times, and all solutions replaced every 2 days. The experiment lasted for 21 days. Three seedlings washed with deionized water were randomly selected at each treatment concentration to measure the shoot height, root length, shoot dry weight, and root dry weight.

\section{Determination of $\mathrm{Cu}$ Concentrations}

The method of analyzing the copper content in Phragmites seedings is shown as follows. Firstly, the seedlings were washed then dried via baking, and then the dried samples were homogenized. Next, they were transferred to a Microwave Digestion System (MARS-5; CEM, Matthews, North Carolina) for mineralization with $\mathrm{HNO}_{3}(67 \%)-\mathrm{HCl}(30 \%)-\mathrm{HF}(49 \%)$ acids $(5: 2: 2, \mathrm{~V} / \mathrm{V} / \mathrm{V})$. Lastly, analysis of the mineralized samples was conducted using Inductively Coupled Plasma-Atomic Emission Spectrometry (ICP-AES) (Perkin Elmer Optima 5300DV, Waltham, Massachusetts).

Physiological Measurements of Phragmites Seedlings under Copper Stress

According to Heath et al. (Heath and Packer 1968), lipid peroxidation was assayed by determining the content of MDA in the functional leaf. A Phragmites leaf sample $(0.1 \mathrm{~g})$ was homogenized with $5 \mathrm{~mL}$ of $10 \%$ trichloroacetic acid (TCA) solution and a small amount of quartz sand in the mortar. The homogenate was poured into a glass tube and centrifuged at $4000 \mathrm{r} / \mathrm{min}$ for $15 \mathrm{~min}$. $2 \mathrm{ml}$ of $0.6 \%$ Thiobarbituric acid (TBA) replaced $2 \mathrm{ml}$ of the supernatant in the centrifuge tube, and the new solution was mixed well and kept in a boiling water bath for 15 . The reaction was stopped by cooling and the mixture was centrifuged again. The supernatant was used to measure the absorbance (OD) of the sample at $450 \mathrm{~nm}, 532 \mathrm{~nm}$ and $600 \mathrm{~nm}$ wavelengths in a cuvette.

The EL induced by copper was estimated by measuring the electric conductivity (Pang et al. 2003). Plant samples of Phragmites leaves $(0.1 \mathrm{~g})$ were placed into syringe containing $10 \mathrm{~mL}$ of deionized water. Then, the air between the leaves was exhausted by pumping repeatedly for several minutes. Then pour the samples and water into a beaker and wait for about 10 minutes. The electric conductivity was measured at room temperature (EC1). Thereafter, the beakers containing the fronds were placed in a boiling water $\left(100^{\circ} \mathrm{C}\right)$ bath for $20 \mathrm{~min}$ and then cooled to room temperature, and the electric conductivity was measured again (EC2). The relative electrolyte leakage was calculated using the following formula: $\mathrm{EL}=$ $(E C 1 / E C 2) \times 100$.

FTIR Spectroscopic Analysis

The root, stem, and leaf of Phragmites stressed by copper were separated into different beakers, numbered, and frozen. $4 \mathrm{~g}$ of frozen plant samples was weighed accurately and grinded into powder. Next, the powdered plant sample was transferred to a sealed centrifuge tube, treated in an ice water bath for 20 minutes, and centrifuged for 10 minutes in a 4000 rpm high-speed centrifuge. The precipitate was 
washed once each with iced acetone, iced methanol chloroform, and methanol, and centrifuged again at $4000 \mathrm{rpm}$ for $10 \mathrm{~min}$. After the second centrifugation, the precipitate was frozen, vacuum dried, weighed, and numbered. To determine the spectral information, $2 \mathrm{mg}$ of the dried sample prepared above was thoroughly mixed with $\mathrm{KBr}$. The absorbance of each component of Phragmites was then recorded with a FTIR (as per operator procedure).

Metabolomic Analysis

The extraction of metabolites was carried out as follows: Frozen leaf tissues (100 mg) from each sample group were grinded in $1 \mathrm{~mL}$ solution of methanol/water (1:1) at a frequency of $60 \mathrm{~Hz}$ for 2 minutes. The samples were sonicated for $30 \mathrm{~min}$ and let stood at $-20^{\circ} \mathrm{C}$ for $20 \mathrm{~min}$. Next, the samples were centrifuged for $10 \mathrm{~min}\left(13000 \mathrm{rpm}, 4^{\circ} \mathrm{C}\right)$ and $200 \mu \mathrm{L}$ of the supernatant was drawn with a syringe. Finally, the samples were transferred to the LC injection vial and stored at $-80^{\circ} \mathrm{C}$ until LC-MS analysis. Quality control samples (QC) were prepared by mixing extracts of all samples. All extraction reagents in this experiment were pre-cooled at $-20^{\circ} \mathrm{C}$ before use.

The metabolite data in this experiment were acquired using a liquid-mass spectrometry system composed of Thermo Scientific UltiMate 3000 HPLC in tandem with Thermo Scientific Q-Exactive highresolution mass spectrometer. Analytes were separated using an ACQUITY UPLC BEH C18 column (100 $\mathrm{mm} \times 2.1 \mathrm{~mm}, 1.7 \mu \mathrm{m})$. The mobile phases were $(A)$ water with $0.1 \%$ acetic acid and $(B)$ acetonitrile with $0.1 \%$ acetic acid. Gradient elution was performed at a flow rate of $0.35 \mathrm{~mL} / \mathrm{min}$ under the following program: 0-0.5min, 5\% B; 0.5-7 min, 5-100\% B; 7-8 min, 100\% B; 8-8.1 min, 100-5\% B; 8.1-10 min, 5\%B. The column temperature was kept at $50^{\circ} \mathrm{C}$ and the injection volume was $10 \mu \mathrm{L}$.

\section{Statistical Analysis}

All values in this study were the average of three replicate samples. The MDA concentration was calculated according to the following formula:

MDA concentration $(\mu \mathrm{mol} \cdot \mathrm{L}-1=6.45 \times(D 532-D 600)-0.56 \times D 450)$.

where $D 532, D 600$ and $D 450$ represent the optical density values at the wavelengths of 532,600 , and 450 $\mathrm{nm}$, respectively.

SPSS (Ver.25.0, US) software was used to perform statistical analyses. The data was analyzed using one-way ANOVAs and least significant difference (LSD) test was used to determine the significant differences between treatments $(P<0.05)$.

\section{Results}

Distribution of Copper and Effect on P.australis Growth 
In this study, the results showed that the copper content in the roots, stems, and leaves of P.australis was constantly increasing as the copper concentration increased (Fig. 1). When the copper concentration changed from $5 \mathrm{mg} \cdot \mathrm{I}^{-1}$ to $10 \mathrm{mg} \cdot \mathrm{l}^{-1}$, the copper content in the roots, stems, and leaves of P.australis increased by $44.53 \%, 113.67 \%$, and $105.32 \%$ respectively. Moreover, copper content in roots, stems and leaves increased by $16.57 \%, 18.7 \%$, and $28.6 \%$ respectively when the copper concentration increased from $10 \mathrm{mg} \cdot \mathrm{I}^{-1}$ to $20 \mathrm{mg} \cdot \mathrm{l}^{-1}$. It can be seen that the copper content significantly increased in all parts of P.australis as the copper concentration changed from $5 \mathrm{mg} \cdot \mathrm{I}^{-1}$ to $10 \mathrm{mg} \cdot \mathrm{I}^{-1}$, however the accumulation rate slowed down as the copper concentration changed from $10 \mathrm{mg} \cdot \mathrm{I}^{-1}$ to $20 \mathrm{mg} \cdot \mathrm{I}^{-1}$.

As shown in Table 1, in response to copper stress, the shoot height and root length of Paustralis had a tendency to decrease gradually from $5 \mathrm{mg} \cdot \mathrm{l}^{-1}$ to $20 \mathrm{mg} \cdot \mathrm{l}^{-1}$ compared to the control group. Additionally, Table 1 shows that shoot dry weight and root dry weight decreases with increasing copper concentration.

Table 1

Effect of copper stress on shoot height, root length, shoot dry weight and root dry weight of P.australis seedlings.

\begin{tabular}{|c|c|c|c|c|}
\hline & Control & $5 \mathrm{mg} \cdot \mathrm{l}^{-1}$ & $10 \mathrm{mg} \cdot \mathrm{l}^{-1}$ & $20 \mathrm{mg} \cdot \mathrm{l}^{-1}$ \\
\hline Shoot height (cm) & $36.0 \pm 1.80^{\mathrm{a}}$ & $26.0 \pm 1.45^{b}$ & $23.2 \pm 1.23^{c}$ & $19.8 \pm 0.33^{d}$ \\
\hline Root length $(\mathrm{cm})$ & $13.7 \pm 0.75^{\mathrm{a}}$ & $12.6 \pm 0.72^{\mathrm{a}}$ & $12.2 \pm 0.68^{\mathrm{ab}}$ & $11.0 \pm 0.81^{c}$ \\
\hline Shoot dry weight (mg) & $110.8 \pm 6.30^{a}$ & $84.3 \pm 5.16^{b}$ & $66.0 \pm 3.12^{c}$ & $52.4 \pm 4.20^{d}$ \\
\hline Root dry weight (mg) & $39.5 \pm 6.20^{\mathrm{a}}$ & $28.0 \pm 2.41^{b}$ & $25.1 \pm 3.94^{b c}$ & $18.2 \pm 3.20^{\mathrm{C}}$ \\
\hline
\end{tabular}

Different lowercase letters within a column indicate a significant difference between the treatments $(\mathrm{p}<$ 0.05). Data shown are the average of three replications $(n=3)$.

Effect of Copper on EL and MDA in P.australis Leaves

In this study, the MDA content of P.australis leaves increased with an increase in copper concentration (Fig. 2a). As shown in Fig. 2b, a continuous increase in copper concentration led to the increase of EL. The results above reflect that excess copper can exacerbate the damage of cell tissues.

FTIR Analysis of P.australis Seedlings

As shown in Fig. 3a, the absorption peaks of P.australis leaves mainly changed in two places under copper stress. The hydroxyl (O-H) absorption peak of the control group was $3429 \mathrm{~cm}^{-1}$, and the absorption peak moved to $3417 \mathrm{~cm}^{-1}$ under a copper stress of $5 \mathrm{mg} / \mathrm{L}$. Moreover, the absorption peaks of the control group was $1644 \mathrm{~cm}^{-1}$, and the absorption peak moved to $1655 \mathrm{~cm}^{-1}$ under a copper stress of $5 \mathrm{mg} / \mathrm{L}$. 
In addition, Fig. 3b shows that the main FTIR changes in P.australis stems were the $0-\mathrm{H}$ absorption peak at $3414 \mathrm{~cm}^{-1}-3401 \mathrm{~cm}^{-1}$ and the N-H amide absorption peak at $1639 \mathrm{~cm}^{-1}-1633 \mathrm{~cm}^{-1}$. Figure $3 \mathrm{c}$ also shows that the $\mathrm{O}-\mathrm{H}$ absorption peak of P.australis roots was at $3388 \mathrm{~cm}^{-1}-3403 \mathrm{~cm}^{-1}$, and the C-C or C-O group absorption peak was at $1124 \mathrm{~cm}^{-1}-1140 \mathrm{~cm}^{-1}$.

Metabolomic Analysis of P.australis under Copper Stress

In the metabolomic results, univariate analysis of fold-change and $T$ statistical were used to test $p$-value to screen the differentially expressed metabolites. The screening criteria are ratio $>=2$ or ratio $<=1 / 2, p$ value $<0.05$ and the fold change is the ratio of average content of metabolites in the two groups. The results reflected that there were a total of 228 differential metabolites in the positive ion sample group, which can be divided into 64 up-regulated differential metabolites and 164 down-regulated differential metabolites. Meanwhile, a total of 217 differential metabolites were in the negative ion sample group, of which 80 were up-regulated differential metabolites and 137 were down-regulated differential metabolites. In general, pathway analysis is based on the metabolic pathways of the Kyoto Encyclopedia of Genes and Genomes (KEGG) database. We mapped the differential metabolites to the KEGG database to obtain the enrichment results of their metabolic pathways. By estimating pathway enrichment analysis of differential metabolites, we obtained 73 metabolic pathways and 1609 metabolites in the positive ion group, of which 215 are differential metabolites. At the same time, there were 69 metabolic pathways and 1044 metabolites in the negative ion group, which included 171 differential metabolites. For the screening of significant difference metabolic pathways, the significant difference metabolic pathway was selected as the pathway with a larger $p$-value $(p<0.05)$. Significantly different metabolic pathways in the positive ion group are: Starch and sucrose metabolism, Arginine and proline metabolism, Tryptophan metabolism, ABC transporters, Galactose metabolism, Tyrosine metabolism, Isoquinoline alkaloid biosynthesis, alphaLinolenic acid metabolism, Monobactam biosynthesis, Lysine degradation, Aminoacyl-tRNA biosynthesis, and Photosynthesis. Significantly different metabolic pathways in the negative ion group are: Lysine degradation, Flavone and flavonol biosynthesis and Arginine biosynthesis.

The Analysis of Arginine Biosynthesis of P.australis under Copper Stress

As shown in Fig. 5a, there are three differential metabolites in the arginine biosynthesis pathway. Glutamine and N-Acetyl-L-glutamate 5-semialdehyde are down-regulated metabolites, which are involved in citrulline synthesis and ornithine synthesis respectively. Arginine is an up-regulated metabolite, which is involved in both synthesis processes mentioned. Citrulline and ornithine also participate in the synthesis of arginine. In this study, the synthesis of arginine was divided into two pathways: firstly the direct catabolization of citrulline into arginine, and secondly the circular pathway composed of ornithine, citrulline, L-Argininosuccinate, and arginine (Fig. 5a).

The Analysis of Flavone and Flavonol Biosynthesis of P.australis Copper Stress

In this study, as shown in Fig. 5b, there are 6 differential metabolites in the biosynthesis of flavonoids and flavonols under copper stress, of which ayarin was the only up-regulated compound. And ayarin was 
involved in the flavonol resistance mechanism of P.australis under copper stress. The result showed that during the biosynthesis of ayarin, quercetin was firstly methylated to form 3-0-methylquercetin, then transformed into 3,7-0-Dimethyquercetagetin and finally obtain ayarin. (Fig. 5b). Moreover,apigenin and kaempferol produced in the process of flavonoids biosynthesis. The results also showed that apigenin can be transformed into Cosmosiin, Apin, Isovitexin and Vitexin and they were all down-regulated metabolites. And kaempferol was transformed into quercetin conducted by flavonoid 3'-hydroxylase $\left(\mathrm{F} 3^{\prime} \mathrm{H}\right)$ and flavonoid $3^{\prime}, 5^{\prime}$-hydroxylase $\left(\mathrm{F}^{\prime} \mathrm{S}^{\prime} \mathrm{H}\right)$, and quercetin continued to undergo methylation and a series of reactions to finally form ayarin. Meanwhile, kaempferol can also be converted to kaempferin by UDP-glycosyltransferase 78D1 (UGT78D1), kaempferin was down-regulated metabolite.

\section{Discussion}

The distribution of copper reflect that P.australis has a great potential to accumulate $\mathrm{Cu}$ in their body parts. This is reflective of the addition of copper inhibiting the growth of Paustralis due to large amounts of copper accumulation in the cells (Ju et al. 2019, Saleem et al. 2020, Liu et al. 2018).

MDA is the oxidation product of lipid peroxidation, indicating the generation of free radicals and reflecting the degree of damaged membranes which are caused by abiotic stress (Riaz et al. 2021, Ohkawa H 1979). Lipid peroxidation is mediated by free radicals (Slater 1984a;b), which is the best measure (Halliwell 1991) to test the damage that is caused by increasing reactive oxygen species (ROS). Judging by the growth trend of MDA, it can be inferred that the increasing copper content will induce a large amount of ROS in P.australis leaves. And ROS can cause lipid peroxidation and cell membrane damage. Kumar et al. (Kumar et al. 2020) have reported that cell damage can increase the permeability of ions in cells and lead to the death of the cell. The degree of copper damage to cells of P.australis leaves can be assessed by measuring EL in the cells. In this study, MDA content and EL all increased with increasing copper concentration. Farid et al. (Farid et al. 2020) concluded that increasing chromium content in the soil can promote the production of EL and MDA in sunflower tissues. In this project, the continuous increase of MDA and EL can reflect the activation of the oxidative stress response of Paustralis leaves, and the antioxidant defense system can be activated to resist oxidative stress. Saleem et al. (Saleem et al. 2020) found the EL and MDA contents of the Hibiscus cannabinus L. to increase under copper stress, and excess copper induced oxidative damage in Hibiscus cannabinus L. roots and leaves. However, they found that antioxidants (SOD, POD, CAT and APX) can eliminate the activity of ROS when their content was up to $120 \mu \mathrm{mol} \cdot \mathrm{L}^{-1}$, which shows that the active antioxidant systems can help Hibiscus cannabinus L. resist copper stress (Saleem et al. 2020). Zhu et al. (Zhu et al. 2020) reported that the Cd content in cotton roots and leaves is positively correlated with MDA and EL, while negatively correlated with SOD, CAT, chlorophyll, and photosynthetic parameters, and the antioxidant mechanism of cotton can be enhanced by adding biochar and biofertilizer. Therefore, in this study, the increase of MDA and EL in P.australis leaves under copper stress indicates that the cells have undergone lipid peroxidation reactions triggered by free radicals, leading to increasing cell damage, and it is speculated that the anti-oxidant defense system of P.australis leaves are activated at this time. 
Infrared spectroscopy can identify the functional groups contained in a molecule (Zhang et al. 2020). Dhivya et al. (Dhivya 2017) have reported that the change of O-H may be related to the production of polyphenols and flavonoids, and another study shows that phenolic compounds and flavonoids are considered antioxidants and can be used as reducing agents and free radical scavengers (Gupta and Gupta 2011). At the same time, it is reported that the antioxidant activity of phenolic compounds and flavonoids is proportional to the presence of $\mathrm{O}-\mathrm{H}$ in the sample, and the position of $\mathrm{O}-\mathrm{H}$ can also affect free radical scavenging activity (Patle et al. 2020, S. Meenakshi 2009, Balasundram,Sundram and Samman 2006). Alica Bartošová et al. (Alica Bartošová 2015) showed that $1644 \mathrm{~cm}^{-1}$ is the characteristic band of protein spectrum. Yu et al. (Yu et al. 2020) analyzed infrared spectra and found that the absorbance of high concentration of $\mathrm{Cd}$ in the roots is greater than that of low concentration at the absorption band of $1631 \mathrm{~cm}^{-1}-1637 \mathrm{~cm}^{-1}$. High concentration of Cd can induce C.Canadensis (L.) Cronq seedlings to produce many proteins, amino acids, and other substances, and can also enhance stress resistance, provide nitrogen sources, reduce heavy metal toxicity and stabilize the internal environment by means of osmotic adjustment. Therefore, in this study, the FTIR results demonstrate that the $\mathrm{O}-\mathrm{H}$ changes in P.australis leaves are related to the production of polyphenols and flavonoids, and the content of proteins and amino acids have an influence on the changes of absorption band near the 1644 $\mathrm{cm}^{-1}$ under copper stress. According to Yu et al. (Yu et al. 2017), FTIR analysis shows that under Cd stress, the $\mathrm{O}-\mathrm{H}$ absorption peak of V.zizanioides roots is higher than that of the control group. The O-H of the root cells was complexed with $\mathrm{C}$, which formed stable compounds to improve the plant's resistance to $\mathrm{Cd}$. In this study, it is speculated that the increased $\mathrm{O}-\mathrm{H}$ in the roots of P.australis are complexed with $\mathrm{Cu}$ ions to improve the tolerance of the roots under copper stress.

In this study, infrared spectroscopy detected the changes of the functional groups, some of which were related to amino acids and flavonoids in P.australis leaves. By analyzing the metabonomic results, we found that many amino acid-related pathways were significantly enriched, one of which being the arginine biosynthesis pathway. The metabolic activity of the compounds in the arginine biosynthesis pathway can not only maintain the balance of citrulline and ornithine in P.australis leaves, but also urge P.australis leaves to accumulate a large amount of arginine. These amino acids can not only chelate heavy metals but can also have antioxidant effects. In addition, the flavonoids and flavonols biosynthesis pathway in the metabolome revealed the production process of specific flavonoids and flavonols and their changes in response to copper stress. Interestingly, these compounds also have high antioxidant activities. Therefore, this project will mainly analyze the arginine biosynthesis pathway and the flavonoids and flavonols biosynthesis pathway to explain their resistance mechanisms in P.australis leaves under copper stress.

In the arginine biosynthesis pathway, several studies have shown that a large amount of arginine in plants can reduce toxicity by chelating heavy metal ions. At the same time, arginine can also synthesize antioxidant peptides with other substances to inhibit the destruction caused by ROS and the peroxidation of essential fatty acids (Rani,Pooja and Pal 2018, Nasibi et al. 2013, Koilraj,Kalusulingam and Sasaki 2019, Maestri,Marmiroli and Marmiroli 2016). In the first pathway, the citrulline can be converted into 
arginine. Hartman et al. (Hartman et al. 2019) have reported that citrulline is a precursor of arginine in the pathway of citrulline catabolizing into arginine. In the second circular pathway, ornithine is firstly converted to citrulline by the catalysis of ornithine transcarbamoylase (OTC). Then, L-Argininosuccinate is formed by the connection of aspartic acid with citrulline conducted via argininosuccinate synthase (ASS1). Finally, the synthesis of arginine is catalyzed by arginosuccinate lyase (ASL), and arginine is sequentially catabolized into ornithine by arginase (Winter et al. 2015, Joshi and Fernie 2017, Monne et al. 2015). According to Fig. 5a, arginine can also be consumed to transformed into citrhlline. Therefore, it is inferred that the second circular pathway dominates the process of arginine accumulation. And the accumulated arginine was used to resist copper stress.

According to differential intermediate metabolites in plants, there are two pathways for the synthesis of citrulline in plants: the glutamine synthesis pathway and the arginine synthesis pathway (Domingos et al. 2015, Pandey 2018, Fragkos 2018). In the first pathway, Joshi et al. (Joshi and Fernie 2017) report that glutamine accumulation is a necessary prerequisite for the synthesis of citrulline through carbamoyl phosphate synthetase (CPS). In the second pathway, arginine can be oxidized to citrulline by the catalysis of nitric oxide synthase (NOS) according to Maurya et al. (Maurya and Rani 2017). In this study, glutamine was a down-regulated metabolite, and the biosynthesis of citrulline was reduced in the glutamine synthesis pathway. However, arginine was an up-regulated metabolite, which increased citrulline synthesis. The two pathways jointly maintained the stability of citrulline in P.australis leaves. Citrulline can maintain nitrogen homeostasis by playing a role in plant nitrogen transport under abiotic stress and maintaining cell osmotic pressure, and it is also an effective free radical scavenger (Joshi and Fernie 2017, Breuillard,Cynober and Moinard 2015).

In addition, the synthesis of ornithine is also divided into two pathways: the glutamate synthesis pathway and the arginine synthesis pathway (Monne et al. 2015, Chen et al. 2019). In the first pathway, Winter et al. (Winter et al. 2015) found that glutamate synthesizes ornithine in a cyclic fashion through several acetylation intermediates. In the second pathway, Singh et al. (Singh et al. 2020) showed that arginine synthesizes ornithine through arginase. In this study, N-Acetyl-L-glutamate 5-semialdehyde, a key acetylation intermediate in the glutamate pathway, was down-regulated, which indicates that the accumulation of ornithine was reduced in this pathway. In the arginine pathway, arginine was an upregulated metabolite, which promoted the accumulation of ornithine. It can be speculated that the two pathways worked together to maintain the balance of ornithine. Studies show that excessive accumulation of ornithine can not only cause the toxicity of plants, but also limit the synthesis of polyamines. Therefore, it is necessary to maintain homeostasis of ornithine in plants. A proper amount of ornithine can be used as a precursor of polyamines, a signal molecule and a nitrogen carrier in plants, and the nitrogen carried can resist oxidative damage by enhancing the antioxidant defense system (Winter et al. 2015, Joshi and Fernie 2017, Pandey 2018, Jortzik et al. 2010).

In the flavonoids and flavonols biosynthesis pathway, flavonoids have an important function in many plants, such as pigmentation, preventing dormancy, improving fertility, protecting from ultraviolet rays, 
defending against plant pathogens, and preventing biological and abiotic stress. Flavone and flavonol are flavonoids (Iwashina 2003, Jia et al. 2012).

Ayarin is a flavonol derived from the gradual methylation of quercetin (Vitalini et al. 2011). Flavonols can act as antioxidants and activate the antioxidant system when plants resist adverse environment and abiotic stresses, and can also eliminate oxidative stress induced by ROS (Zhang et al. 2020, Watkins,Hechler and Muday 2014). Several studies have shown that as a precursor of ayarin, quercetin can also inhibit lipid peroxidation by scavenging ROS and chelating metal ions which can cause the production of ROS (Ishige,Schubert and Sagara 2001, Kato et al. 2016, Jefrey B. Harborne 2000). It is mentioned above that quercetin forms ayarin via the process of 3-Omethylation. Although the oxidation ability of ayarin is weaker than quercetin, the process of 3-Omethylation greatly improves the free radical scavenging ability of ayarin. This is because methylated quercetin is an effective metal chelating agent that will chelate Cu ions to form a complex (Vitalini et al. 2011, Kato et al. 2016, Pekal,Biesaga and Pyrzynska 2011, Bukhari et al. 2009). Therefore, in this study, it is speculated that P.australis resists oxidative stress by exerting a higher antioxidant capacity through the chelation of ayarin.

As a naturally occurring flavonoid in plants, apigenin has significant antioxidant activity, which can have an effect on scavenging free radicals to inhibit the oxidative stress response of plants (Dou et al. 2020). Studies show that apigenin can also combine with sugar to form Cosmosiin, Apin, Isovitexin and Vitexin and other compounds, and these compounds are glycosides naturally occurring in plants (Meyer et al. 2006, Ali et al. 2017, Peng et al. 2008). The researches also show that apigenin should have decreased when these glycosides were down-regulated. However, apigenin have no significant changes. And studies have found that chalcone synthase (CHS) and flavone synthase I (FSI) are the key enzymes involved in the production of apigenin in the process of flavonoid biosynthesis (Li,Feng, et al. 2020, Yan et al. 2014). Therefore, it is speculated that the apigenin content in P.australis leaves stayed stable because the process of flavonoids biosynthesis can produce apigenin when apigenin was consumed by other reactions.

Kaempferol is also a natural flavonoid with powerful antioxidant activity (Deng et al. 2019). Studies show that kaempferin is the derivative of kaemferol, and UGT78D1 is as the key enzyme to conduct kaempferol transform into kaempferin (Li,Hossain, et al. 2020, Lee et al. 2017), so kaempferol should have decreased when it was converted into ayarin and kaempferin. However, kaempferol have no significant changes in the present research. Dong et al. (Dong and Lin 2021) have studied that kaempferol is produced in the process of flavonoid biosynthesis and requires the participation of flavonol synthase (FLS), which acts on dihydroflavonols to produce flavonols such as kaempferol. Furthermore, Guo et al. (Guo et al. 2019) have reported that F3'H and F3'5'H can promote the accumulation of quercetin, and F3' $\mathrm{H}$ plays a leading role in this process. Therefore, it is speculated that kaempferol can be produced in the process of flavonoid biosynthesis when kaempferol was consumed by other reactions, which was greatly balance the content of kaempferol in P.australis leaves. By maintaining the content of kaempferol in P.australis leaves and avoiding the decrease of its content, the oxidative stress response caused by copper stress can be resisted. 


\section{Conclusions}

The main goal of this report is to evaluate the resistance mechanism of Phragmites to coppr stress during growth and development from the aspect of metabolomics analysis. Here, we studied the variation of the physiological indicators of Phragmites leaves and found that the content of MDA and EL gradually increased with the increase of copper concentration, which reflected that the degree of oxidative damage of Phragmites leaves under copper stress was increasing. Additionally, we used the FTIR to research the change of chemical composition in the roots, stems and leaves of Phragmites seedlings, the results showed that flavonoids and amino acids were the main increased substances in Phragmites leaves, which is helpful to explain how plants show tolerance to copper stress. Besides, by analying the metabolomics results to identify significant differential metabolic pathways and differential metabolites that were significantly up-regulated or down-regulated in the corresponding pathways, including Arginine Biosynthesis,Flavone and Flavonol Biosynthesis $\square$ arginine and ayarin and so on, which were all related to the resistance of Phragmites leaves. This project is devoted to improve the understanding of the physiological and molecular mechanisms involved the process of growth and development of Phragmites leaves under copper stress, and provided a theoretical basis for improving the resistance mechanism and repair performance of Phragmites to heavy metal.

\section{Declarations}

Acknowledgements: This work was supported by National Natural Science Founda- tion of China (No. 51608246), and the Open Project of State Key Laboratory of Urban Water Resource and Environment, Harbin Institute of Technology (No. QA201715).

Conflict of interest The authors declare that they have no conflict of interest.

\section{References}

1. Agati G, Brunetti C, Fini A, Gori A, Guidi L, Landi M, Sebastiani F, Tattini M (2020) Are Flavonoids Effective Antioxidants in Plants? Twenty Years of Our Investigation. Antioxidants (Basel) 9(11)10.3390/antiox9111098

2. Ali F, Rahul, Naz F, Jyoti S, Siddique YH (2017) Health functionality of apigenin: A review. International Journal of Food Properties 20(6):1197-123810.1080/10942912.2016.1207188

3. Alica Bartošová LB, and Kristína Gerulová (2015) < CHARACTERISATION OF POLYSACHARIDES AND LIPIDS FROM SELECTED GREEN ALGAE SPECIES BY FTIR-ATR SPECTROSCOPY.pdf>. Research Papers Faculty of Materials Science and Technology Slovak University of Technology 23(36):97102

4. Arbona V, Manzi M, de Ollas C, Gomez-Cadenas A (2013) Metabolomics as a Tool to Investigate Abiotic Stress Tolerance in Plants. International Journal of Molecular Sciences 14(3):4885491110.3390/ijms14034885 
5. Balasundram N, Sundram K, Samman S (2006) Phenolic compounds in plants and agri-industrial byproducts: Antioxidant activity, occurrence, and potential uses. Food Chemistry 99(1):19120310.1016/j.foodchem.2005.07.042

6. Bonanno G (2013) Comparative performance of trace element bioaccumulation and biomonitoring in the plant species Typha domingensis, Phragmites australis and Arundo donax. Ecotoxicology and Environmental Safety 97:124-13010.1016/j.ecoenv.2013.07.017

7. Breuillard C, Cynober L, Moinard C (2015) Citrulline and nitrogen homeostasis: an overview. Amino Acids 47(4):685-69110.1007/s00726-015-1932-2

8. Bukhari SB, Memon S, Mahroof-Tahir M, Bhanger MI (2009) Synthesis, characterization and antioxidant activity copper-quercetin complex. Spectrochimica acta. Part A, Molecular and biomolecular spectroscopy 71(5):1901-610.1016/j.saa.2008.07.030

9. Carricondo JM, Oliver-Villanueva JV, Turegano JV, Gonzalez JA, Mengual J (2020) Use of Phragmites australis for controlling phosphorus contamination in anthropogenic wetland ecosystems. Environmental Technology 10.1080/09593330.2020.1720311

10. Chen D, Shao Q, Yin L, Younis A, Zheng B (2019) Polyamine Function in Plants: Metabolism, Regulation on Development, and Roles in Abiotic Stress Responses. Frontiers in Plant Science 910.3389/fpls.2018.01945

11. Deng S-P, Yang Y-L, Cheng X-X, Li W-R, Cai J-Y (2019) Synthesis, Spectroscopic Study and Radical Scavenging Activity of Kaempferol Derivatives: Enhanced Water Solubility and Antioxidant Activity. International Journal of Molecular Sciences 20(4)10.3390/ijms20040975

12. Dhivya KKS (2017) < Screening of phytoconstituents, UV-VIS Spectrum and FTIR analysis of Micrococca mercurialis (L.) Benth.pdf>. International Journal of Herbal Medicine: 40-44

13. Dixon RA, Strack D (2003) Phytochemistry meets genome analysis, and beyond. Phytochemistry 62(6):815-610.1016/s0031-9422(02)00712-4

14. Dogan Y, Baslar S, Ugulu I (2014) A STUDY ON DETECTING HEAVY METAL ACCUMULATION THROUGH BIOMONITORING: CONTENT OF TRACE ELEMENTS IN PLANTS AT MOUNT KAZDAGI IN TURKEY. Applied Ecology and Environmental Research 12(3):627-63610.15666/aeer/1203_627636

15. Domingos P, Prado AM, Wong A, Gehring C, Feijo JA (2015) Nitric Oxide: A Multitasked Signaling Gas in Plants. Molecular Plant 8(4):506-52010.1016/j.molp.2014.12.010

16. Dong N-Q, Lin H-X (2021) Contribution of phenylpropanoid metabolism to plant development and plant-environment interactions. Journal of Integrative Plant Biology 63(1):18020910.1111/jipb.13054

17. Dou X, Zhou Z, Ren R, Xu M (2020) Apigenin, flavonoid component isolated from Gentiana veitchiorum flower suppresses the oxidative stress through LDLR-LCAT signaling pathway. Biomedicine \& Pharmacotherapy 12810.1016/j.biopha.2020.110298

18. Farid M, Ali S, Rizwan M, Yasmeen T, Arif MS, Riaz M, Saqib M, Rehman MZu, Ayub MA (2020) COMBINED EFFECTS OF CITRIC ACID AND 5-AMINOLEVULINIC ACID IN MITIGATING CHROMIUM 
TOXICITY IN SUNFLOWER (Helianthus annuus L.) GROWN IN Cr SPIKED SOIL. Pakistan Journal of Agricultural Sciences 57(2):477-48810.21162/pakjas/20.9332

19. Farooq MA, Islam F, Ali B, Najeeb U, Mao B, Gill RA, Yan G, Siddique KHM, Zhou W (2016) Arsenic toxicity in plants: Cellular and molecular mechanisms of its transport and metabolism. Environmental and Experimental Botany 132:42-5210.1016/j.envexpbot.2016.08.004

20. Fragkos K (2018) < Citrulline and the Intestine.pdf>. UCL DISCOVERY:1-313

21. Guo L, Gao L, Ma X, Guo F, Ruan H, Bao Y, Xia T, Wang Y (2019) Functional analysis of flavonoid 3 'hydroxylase and flavonoid 3 ',5 '-hydroxylases from tea plant (Camellia sinensis), involved in the Bring hydroxylation of flavonoids. Gene 71710.1016/j.gene.2019.144046

22. Gupta D, Gupta RK (2011) Bioprotective properties of Dragon's blood resin: in vitro evaluation of antioxidant activity and antimicrobial activity. BMC complementary and alternative medicine 11:131310.1186/1472-6882-11-13

23. Halliwell B (1991) REACTIVE OXYGEN SPECIES IN LIVING SYSTEMS - SOURCE, BIOCHEMISTRY, AND ROLE IN HUMAN-DISEASE. American Journal of Medicine 91:S14-S2210.1016/00029343(91)90279-7

24. Hartman JL, Wehner TC, Ma G, Perkins-Veazie P (2019) Citrulline and Arginine Content of Taxa of Cucurbitaceae. Horticulturae 5(1)10.3390/horticulturae5010022

25. Heath RL, Packer L (1968) Photoperoxidation in isolated chloroplasts. I. Kinetics and stoichiometry of fatty acid peroxidation. Archives of biochemistry and biophysics 125(1):189-9810.1016/00039861(68)90654-1

26. Hong J, Yang L, Zhang D, Shi J (2016) Plant Metabolomics: An Indispensable System Biology Tool for Plant Science. International Journal of Molecular Sciences 17(6)10.3390/ijms17060767

27. Hou Q, Ufer G, Bartels D (2016) Lipid signalling in plant responses to abiotic stress. Plant Cell and Environment 39(5):1029-104810.1111/pce.12666

28. Huang X, Wang L, Zhu S, Ho S-H, Wu J, Kalita PK, Ma F (2018) Unraveling the effects of arbuscular mycorrhizal fungus on uptake, translocation, and distribution of cadmium in Phragmites australis (Cav.) Trin. ex Steud. Ecotoxicology and Environmental Safety 149:43-

5010.1016/j.ecoenv.2017.11.011

29. Ishige K, Schubert D, Sagara Y (2001) Flavonoids protect neuronal cells from oxidative stress by three distinct mechanisms. Free radical biology \& medicine 30(4):433-4610.1016/s08915849(00)00498-6

30. Iwashina T (2003) Flavonoid function and activity to plants and other organisms. Uchu Seibutsu Kagaku 17(1):24-44

31. Je€rey B. Harborne CAW (2000) < Advances in -avonoid research since 1992.pdf>. Phytochemistry:481-504

32. Jia L, Wu Q, Ye N, Liu R, Shi L, Xu W, Zhi H, Bin Rahman ANMR, Xia Y, Zhang J (2012) Proanthocyanidins Inhibit Seed Germination by Maintaining a High Level of Abscisic Acid in 
Arabidopsis thaliana. Journal of Integrative Plant Biology 54(9):663-67310.1111/j.1744-

7909.2012.01142.x

33. Jortzik E, Fritz-Wolf K, Sturm N, Hipp M, Rahlfs S, Becker K (2010) Redox regulation of Plasmodium falciparum ornithine delta-aminotransferase. J Mol Biol 402(2):445-5910.1016/j.jmb.2010.07.039

34. Joshi V, Fernie AR (2017) Citrulline metabolism in plants. Amino Acids 49(9):1543$155910.1007 / \mathrm{s} 00726-017-2468-4$

35. Ju W, Liu L, Fang L, Cui Y, Duan C, Wu H (2019) Impact of co-inoculation with plant-growth-promoting rhizobacteria and rhizobium on the biochemical responses of alfalfa-soil system in copper contaminated soil. Ecotoxicology and Environmental Safety 167:218-

22610.1016/j.ecoenv.2018.10.016

36. Kapoor D, Singh S, Kumar V, Romero R, Prasad R, Singh J (2019) Antioxidant enzymes regulation in plants in reference to reactive oxygen species (ROS) and reactive nitrogen species (RNS). Plant Gene 1910.1016/j.plgene.2019.100182

37. Kato K, Ninomiya M, Tanaka K, Koketsu M (2016) Effects of Functional Groups and Sugar Composition of Quercetin Derivatives on Their Radical Scavenging Properties. J Nat Prod 79(7):1808-1410.1021/acs.jnatprod.6b00274

38. Keurentjes JJB (2009) Genetical metabolomics: closing in on phenotypes. Current opinion in plant biology 12(2):223-3010.1016/j.pbi.2008.12.003

39. Khan Zl, Ahmad K, Rehman S, Ashfaq A, Mehmood N, Ugulu I, Dogan Y (2019) Effect of Sewage Water Irrigation on Accumulation of Metals in Soil and Wheat in Punjab, Pakistan. Pakistan Journal of Analytical \& Environmental Chemistry 20(1):60-6610.21743/pjaec/2019.06.08

40. Koilraj P, Kalusulingam R, Sasaki K (2019) Arginine and lysine-functionalized layered double hydroxides as efficient sorbents for radioactive $\mathrm{Co} 2+$ removal by chelate-facilitated immobilization. Chemical Engineering Journal 374:359-36910.1016/j.cej.2019.05.166

41. Kovacik J, Klejdus B, Backor M (2009) Phenolic metabolism of Matricaria chamomilla plants exposed to nickel. Journal of Plant Physiology 166(13):1460-146410.1016/j.jplph.2009.03.002

42. Kovacik J, Klejdus B, Hedbavny J, Backor M (2010) Effect of copper and salicylic acid on phenolic metabolites and free amino acids in Scenedesmus quadricauda (Chlorophyceae). Plant Science 178(3):307-31110.1016/j.plantsci.2010.01.009

43. Kumar A, Dubey AK, Kumar V, Ansari MA, Narayan S, Meenakshi, Kumar S, Pandey V, Shirke PA, Pande V, Sanyal I (2020) Over-expression of chickpea glutaredoxin (CaGrx) provides tolerance to heavy metals by reducing metal accumulation and improved physiological and antioxidant defence system. Ecotoxicology and Environmental Safety 19210.1016/j.ecoenv.2020.110252

44. Kusano M, Yang Z, Okazaki Y, Nakabayashi R, Fukushima A, Saito K (2015) Using Metabolomic Approaches to Explore Chemical Diversity in Rice. Molecular Plant 8(1):586710.1016/j.molp.2014.11.010

45. Lee WJ, Kim J, Lee D, Hong S-W, Lee H (2017) Arabidopsis UDP-glycosyltransferase 78D1overexpressing plants accumulate higher levels of kaempferol 3-0-beta-D-glucopyranoside than wild- 
type plants. Applied Biological Chemistry 60(6):647-65210.1007/s13765-017-0322-8

46. Li J, Hossain MS, Ma H, Yang Q, Gong X, Yang P, Feng B (2020) Comparative metabolomics reveals differences in flavonoid metabolites among different coloured buckwheat flowers. Journal of Food Composition and Analysis 8510.1016/j.jfca.2019.103335

47. Li M-Y, Feng K, Hou X-L, Jiang Q, Xu Z-S, Wang G-L, Liu J-X, Wang F, Xiong A-S (2020) The genome sequence of celery (Apium graveolens L.), an important leaf vegetable crop rich in apigenin in the Apiaceae family. Horticulture Research 7(1)10.1038/s41438-019-0235-2

48. Lin Y-F, Aarts MGM (2012) The molecular mechanism of zinc and cadmium stress response in plants. Cellular and molecular life sciences : CMLS 69(19):3187-20610.1007/s00018-012-1089-z

49. Liu J, Wang J, Lee S, Wen R (2018) Copper-caused oxidative stress triggers the activation of antioxidant enzymes via ZmMPK3 in maize leaves. Plos One 13(9)10.1371/journal.pone.0203612

50. Liu N, Zhong G, Zhou J, Liu Y, Pang Y, Cai H, Wu Z (2019) Separate and combined effects of glyphosate and copper on growth and antioxidative enzymes in Salvinia natans (L.) All. Science of the Total Environment 655:1448-145610.1016/j.scitotenv.2018.11.213

51. Maestri E, Marmiroli M, Marmiroli N (2016) Bioactive peptides in plant-derived foodstuffs. J Proteomics 147:140-15510.1016/j.jprot.2016.03.048

52. Maurya AK, Rani A. 2017. "Nitric Oxide (NO) and Physio-biochemical Adaptation in Plants Against Stress." In Plant Adaptation Strategies in Changing Environment, 347-386.

53. Meyer H, Bolarinwa A, Wolfram G, Linseisen J (2006) Bioavailability of apigenin from apiin-rich parsley in humans. Annals of nutrition \& metabolism 50(3):167-7210.1159/000090736

54. Monne M, Miniero DV, Daddabbo L, Palmieri L, Porcelli V, Palmieri F (2015) Mitochondrial transporters for ornithine and related amino acids: a review. Amino Acids 47(9):1763177710.1007/s00726-015-1990-5

55. Nasibi F, Heidari T, Asrar Z, Mansoori H (2013) Effect of arginine pre-treatment on nickel accumulation and alleviation of the oxidative stress in Hyoscyamus niger. Journal of Soil Science and Plant Nutrition 13(3):680-68910.4067/s0718-95162013005000015

56. Nazir F, Hussain A, Fariduddin Q (2019) Hydrogen peroxide modulate photosynthesis and antioxidant systems in tomato (Solanum lycopersicum L.) plants under copper stress. Chemosphere 230:54455810.1016/j.chemosphere.2019.05.001

57. Ohkawa H ON, Yagi K (1979) < Assay for lipid peroxidation in animal tissues by thiobarbituric acid reaction..pdf>. Anal Biochem:351

58. Pandey N (2018) < Role of Plant Nutrients in Plant Growth and Physiology.pdf>. Plant Nutrients and Abiotic Stress Tolerance:1-31

59. Pang J, Chan GSY, Zhang J, Liang J, Wong MH (2003) Physiological aspects of vetiver grass for rehabilitation in abandoned metalliferous mine wastes. Chemosphere 52(9):1559-7010.1016/s00456535(03)00496-x 
60. Patle TK, Shrivas K, Kurrey R, Upadhyay S, Jangde R, Chauhan R (2020) Phytochemical screening and determination of phenolics and flavonoids in Dillenia pentagyna using UV-vis and FTIR spectroscopy. Spectrochimica Acta Part a-Molecular and Biomolecular Spectroscopy 24210.1016/j.saa.2020.118717

61. Pekal A, Biesaga M, Pyrzynska K (2011) Interaction of quercetin with copper ions: complexation, oxidation and reactivity towards radicals. Biometals : an international journal on the role of metal ions in biology, biochemistry, and medicine 24(1):41-910.1007/s10534-010-9372-7

62. Peng X, Zheng Z, Cheng K-W, Shan F, Ren G-X, Chen F, Wang M (2008) Inhibitory effect of mung bean extract and its constituents vitexin and isovitexin on the formation of advanced glycation endproducts. Food Chemistry 106(2):475-48110.1016/j.foodchem.2007.06.016

63. Pisoschi AM, Pop A (2015) The role of antioxidants in the chemistry of oxidative stress: A review. European Journal of Medicinal Chemistry 97:55-7410.1016/j.ejmech.2015.04.040

64. Rani S, Pooja K, Pal GK (2018) Exploration of rice protein hydrolysates and peptides with special reference to antioxidant potential: Computational derived approaches for bio-activity determination. Trends in Food Science \& Technology 80:61-7010.1016/j.tifs.2018.07.013

65. Riaz M, Kamran M, Fang Y, Wang Q, Cao H, Yang G, Deng L, Wang Y, Zhou Y, Anastopoulos I, Wang X (2021) Arbuscular mycorrhizal fungi-induced mitigation of heavy metal phytotoxicity in metal contaminated soils: A critical review. Journal of Hazardous Materials 40210.1016/j.jhazmat.2020.123919

66. S. Meenakshi DMG, S. Tamil mozhi, M. Arumugam, T. Balasubramanian, (2009)< Total flavanoid and in vitro antioxidant activity of two seaweeds of Rameshwaram coast.pdf >. Global Journal of Pharmacology:59-62

67. Sahin I, E. Akcicek, O. Guner, Y. Dogan and I. Ugulu (2016) < An investigation on determining heavy metal.pdf>. Eurasia. J. Biosci:22-2910.5053/ejobios.2016.10.0.3

68. Saleem MH, Fahad S, Rehman M, Saud S, Jamal Y, Khan S, Liu LJ (2020) Morpho-physiological traits, biochemical response and phytoextraction potential of short-term copper stress on kenaf (Hibiscus cannabinus L.) seedlings. Peerj 810.7717/peerj.8321

69. Samaras L, Sicilia M-A, Garcia-Barriocanal E (2021) Predicting epidemics using search engine data: a comparative study on measles in the largest countries of Europe. Bmc Public Health $21(1) 10.1186 / \mathrm{s} 12889-020-10106-8$

70. Singh S, Kumar V, Kapoor D, Kumar S, Singh S, Dhanjal DS, Datta S, Samuel J, Dey P, Wang S, Prasad $\mathrm{R}$, Singh J (2020) Revealing on hydrogen sulfide and nitric oxide signals co-ordination for plant growth under stress conditions. Physiol Plant 168(2):301-31710.1111/ppl.13002

71. Slater TF (1984a) FREE-RADICAL MECHANISMS IN TISSUE-INJURY. Biochemical Journal 222(1):115

72. Slater TF (1984b) OVERVIEW OF METHODS USED FOR DETECTING LIPID-PEROXIDATION. Methods in Enzymology 105:283-293 
73. Ugulu I (2015) Determination of Heavy Metal Accumulation in Plant Samples by Spectrometric Techniques in Turkey. Applied Spectroscopy Reviews 50(2):113-15110.1080/05704928.2014.935981

74. Ugulu I, Dogan Y, Baslar S, Varol O (2012) Biomonitoring of trace element accumulation in plants growing at Murat Mountain. International Journal of Environmental Science and Technology 9(3):527-53410.1007/s13762-012-0056-4

75. Ugulu I, Unver MC, Dogan Y (2016) DETERMINATION AND COMPARISON OF HEAVY METAL ACCUMULATION LEVEL OF Ficus carica BARK AND LEAF SAMPLES IN ARTVIN, TURKEY. Oxidation Communications 39(1):765-775

76. Unver MC, Ugulu I, Durkan N, Baslar S, Dogan Y (2015) Heavy Metal Contents of Malva sylvestris Sold as Edible Greens in the Local Markets of Izmir. Ekoloji 24(96):13-2510.5053/ekoloji.2015.01

77. Villiers F, Ducruix C, Hugouvieux V, Jarno N, Ezan E, Garin J, Junot C, Bourguignon J (2011) Investigating the plant response to cadmium exposure by proteomic and metabolomic approaches. Proteomics 11(9):1650-166310.1002/pmic.201000645

78. Vitalini S, Flamini G, Valaguzza A, Rodondi G, Iriti M, Fico G (2011) Primula spectabilis Tratt. aerial parts: Morphology, volatile compounds and flavonoids. Phytochemistry 72(11-12):1371137810.1016/j.phytochem.2011.04.010

79. Watkins JM, Hechler PJ, Muday GK (2014) Ethylene-Induced Flavonol Accumulation in Guard Cells Suppresses Reactive Oxygen Species and Moderates Stomatal Aperture. Plant Physiology 164(4):1707-171710.1104/pp.113.233528

80. Winter G, Todd CD, Trovato M, Forlani G, Funck D (2015) Physiological implications of arginine metabolism in plants. Frontiers in Plant Science 610.3389/fpls.2015.00534

81. Wu J, Wang L, Ma F, Yang J, Li S, Li Z (2013) Effects of vegetative-periodic-induced rhizosphere variation on the uptake and translocation of metals in Phragmites australis (Cav.) Trin ex. Steudel growing in the Sun Island Wetland. Ecotoxicology 22(4):608-61810.1007/s10646-013-1052-2

82. Wu J, Wang L, Ma F, Zhao L, Huang X (2019) The speciation and distribution characteristics of Cu in Phragmites australis (Cav.) Trin ex. Steudel. Plant Biology 21(5):873-88110.1111/plb.12989

83. Yadav P, Kaur R, Kanwar MK, Sharma A, Verma V, Sirhindi G, Bhardwaj R (2018) Castasterone confers copper stress tolerance by regulating antioxidant enzyme responses, antioxidants, and amino acid balance in B. juncea seedlings. Ecotoxicology and Environmental Safety 147:72573410.1016/j.ecoenv.2017.09.035

84. Yan J, Yu L, Xu S, Gu W, Zhu W (2014) Apigenin accumulation and expression analysis of apigenin biosynthesis relative genes in celery. Scientia Horticulturae 165:21822410.1016/j.scienta.2013.11.018

85. Ye ZH, Baker AJM, Wong MH, Willis AJ (2003) Copper tolerance, uptake and accumulation by Phragmites australis. Chemosphere 50(6):795-80010.1016/s0045-6535(02)00221-7

86. Yu S-h, Deng H-p, Zhang B, Liu Z-x, Lin J-j, Sheng L, Pan J, Huang L, Qi J-s (2017) Physiological Response of Vetiveria Zizanioides to Cadmium Stress Revealed by Fourier Transform Infrared Spectroscopy. Spectroscopy Letters 10.1080/00387010.2017.1355321 
87. Yu S, Sheng L, Mao H, Huang X, Luo L, Li Y (2020) Physiological response of Conyza Canadensis to cadmium stress monitored by Fourier transform infrared spectroscopy and cadmium accumulation. Spectrochimica Acta Part a-Molecular and Biomolecular Spectroscopy 22910.1016/j.saa.2019.118007

88. Zhang X, Herger AG, Ren Z, Li X, Cui Z (2020) Resistance effect of flavonols and toxicology analysis of hexabromocyclododecane based on soil-microbe-plant system. Chemosphere 25710.1016/j.chemosphere.2020.127248

89. Zhao L, Huang Y, Paglia K, Vaniya A, Wancewicz B, Keller AA (2018) Metabolomics Reveals the Molecular Mechanisms of Copper Induced Cucumber Leaf (Cucumis sativus) Senescence. Environmental Science \& Technology 52(12):7092-710010.1021/acs.est.8b00742

90. Zhu YQ, Wang HJ, Lv X, Zhang YT, Wang WJ (2020) Effects of biochar and biofertilizer on cadmiumcontaminated cotton growth and the antioxidative defense system. Scientific Reports 10(1)10.1038/s41598-020-77142-7

\section{Figures}


a
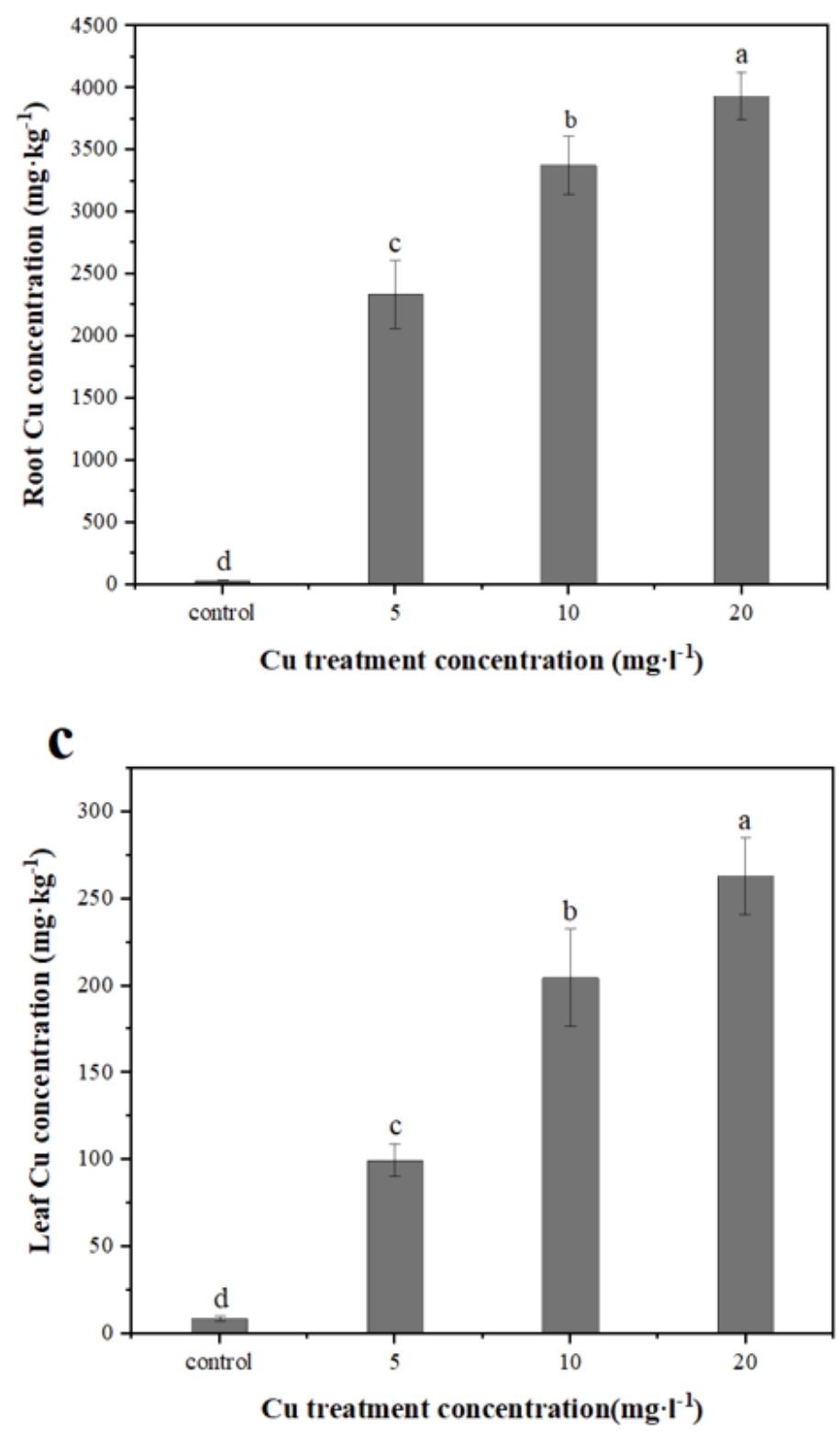

b

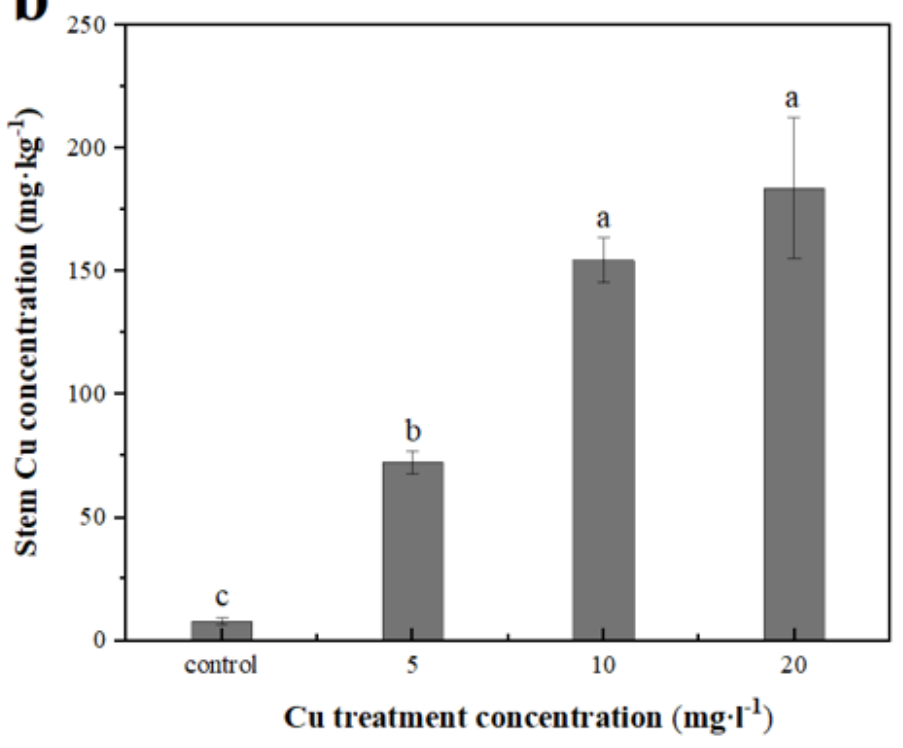

Figure 1

Distribution of copper in (a) roots, (b) stems and (c) leaves of P.australis seedlings. Vertical bars represent $\mathrm{Cu}$ concentration. Different lowercase letters within a column indicate a significant difference between the treatments $(p<0.05)$. Data shown are the average of three replications $(n=3)$. 

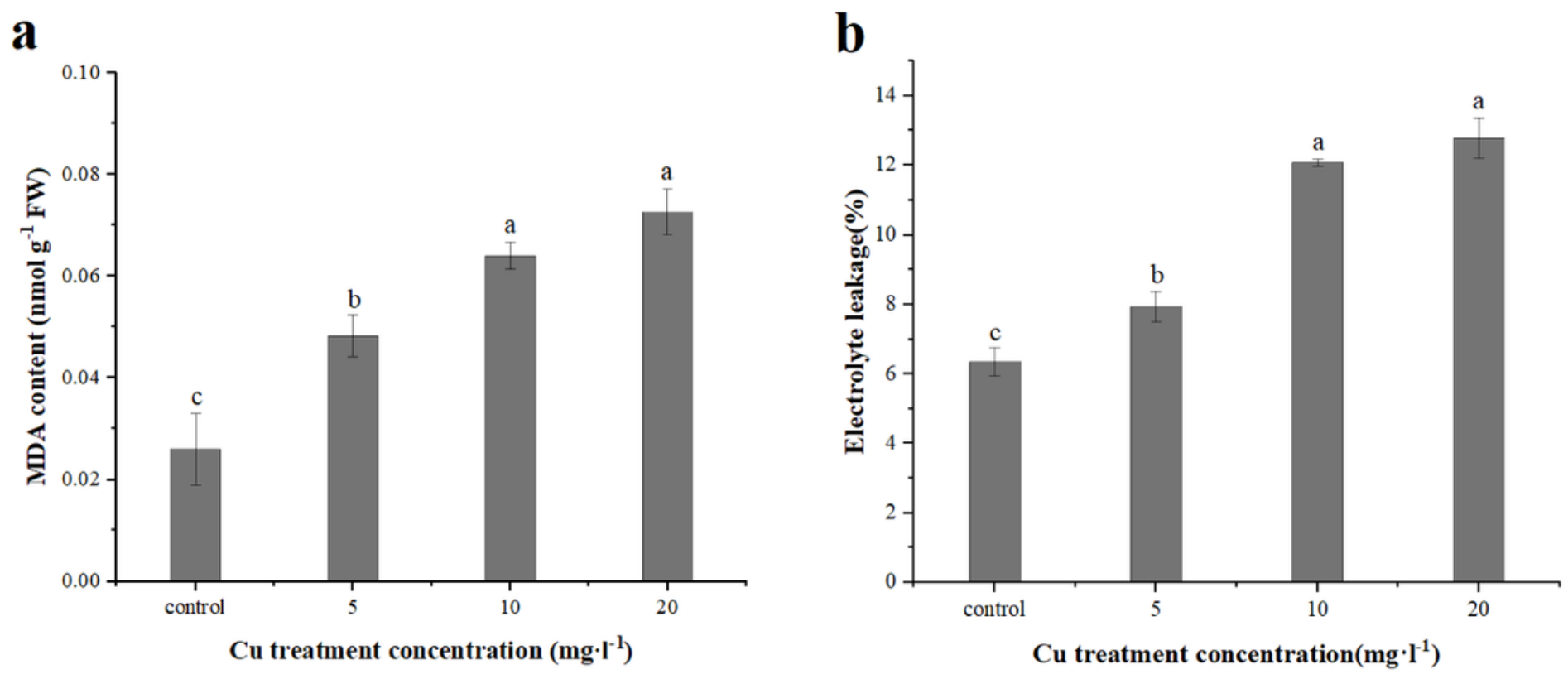

Figure 2

Effects of Cu treatment concentrations on the contents of malondialdehyde (MDA) (a) and electrolyte leakage (EL) (b) in leaves of P.australis seedlings. Different lowercase letters within a column indicate a significant difference between the treatments $(p<0.05)$. Data shown are the average of three replications $(n=3)$. 
a

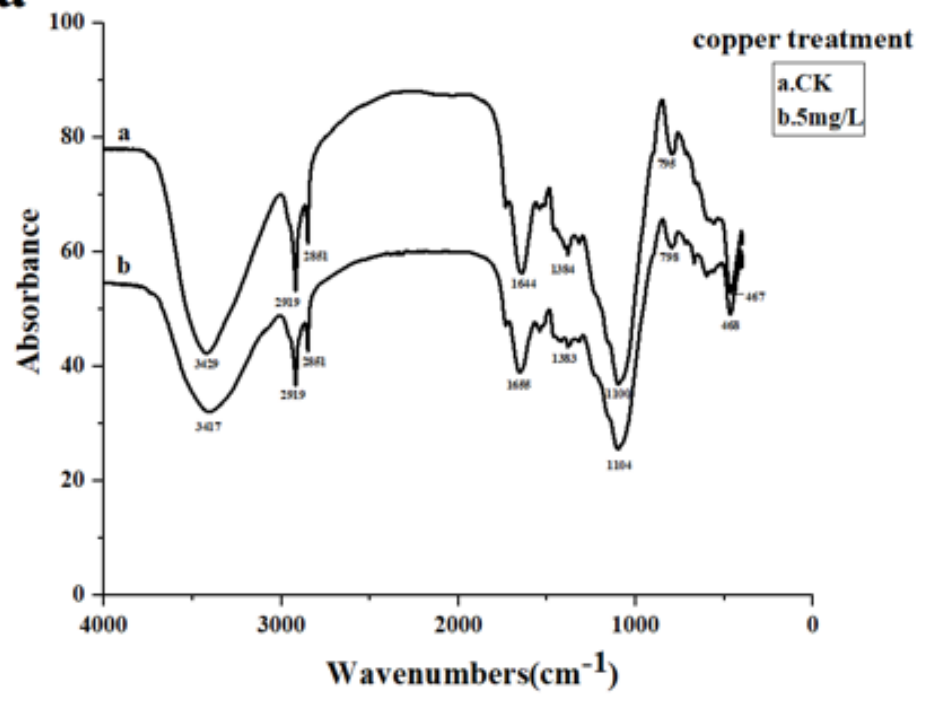

c

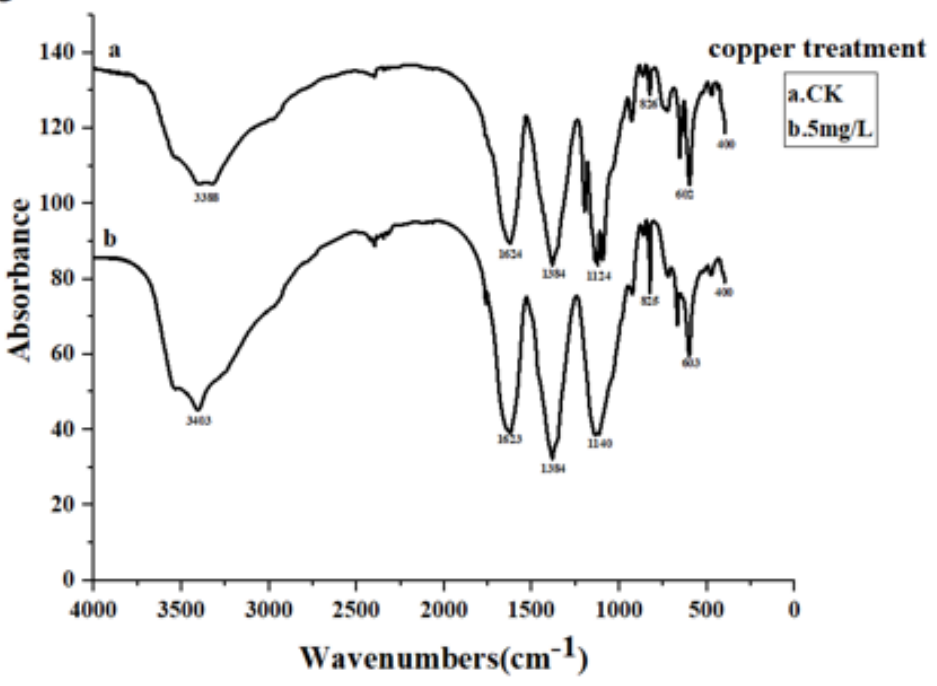

b

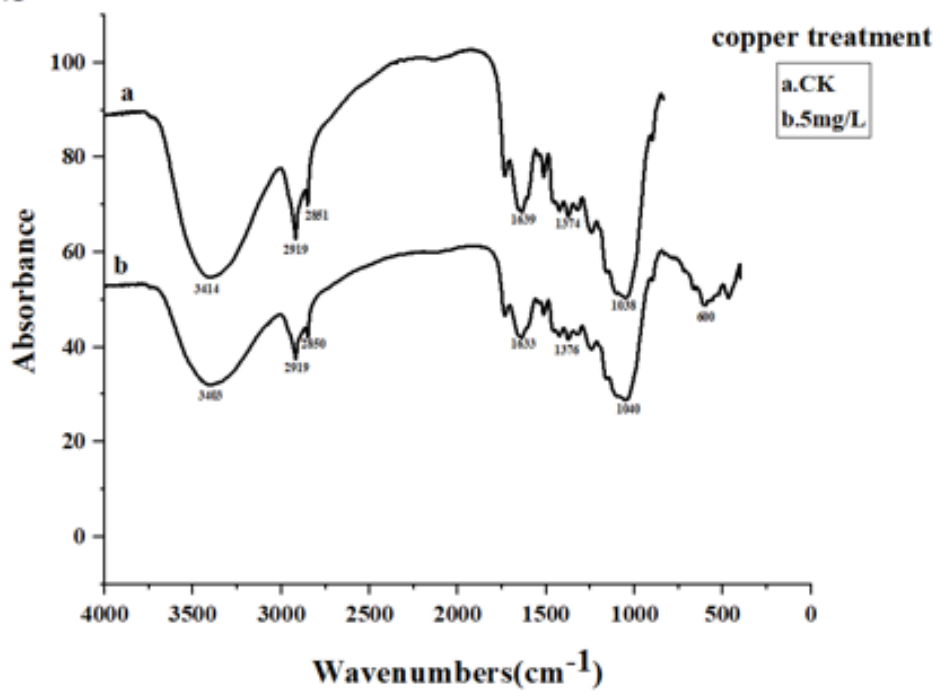

Figure 3

Absorption FTIR spectra in the (a) leaves, (b) stems, and (c) roots of P.australis seedlings by copper treatment. 
T test

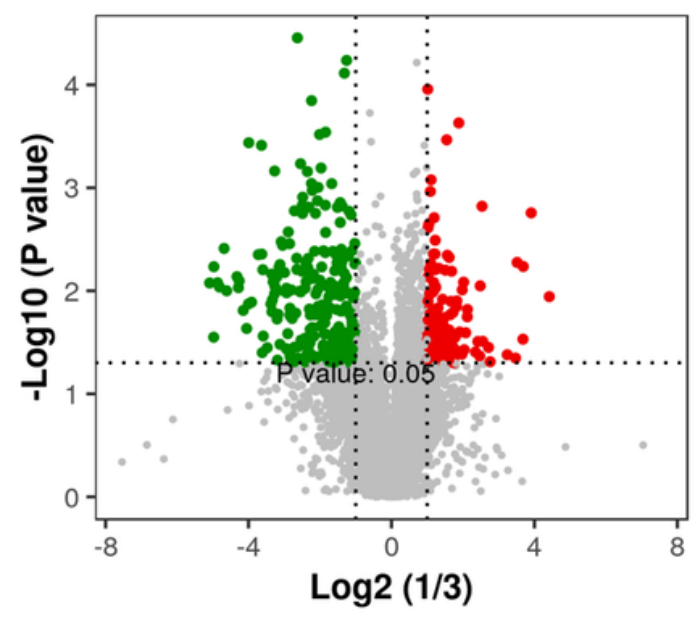

regulated

- down

none

- up b

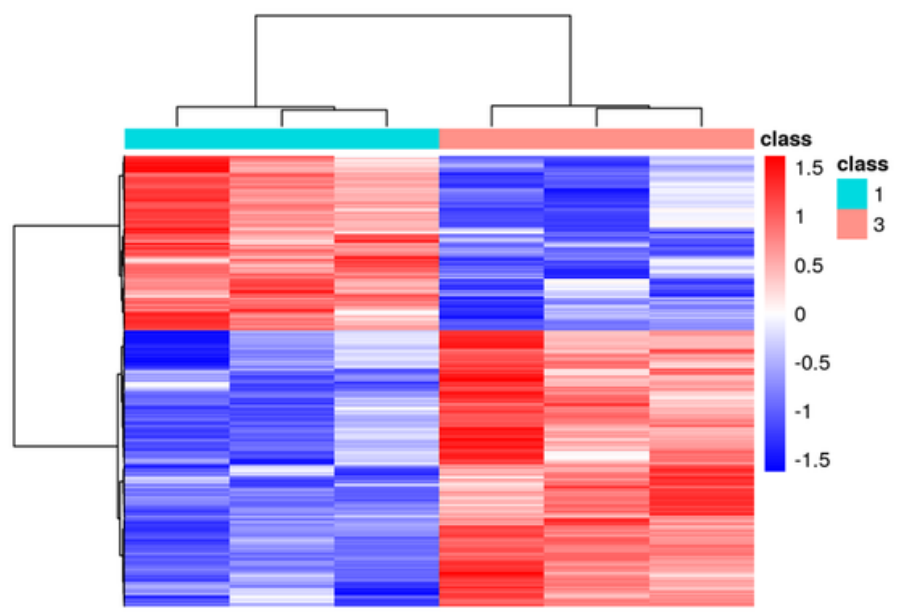

d

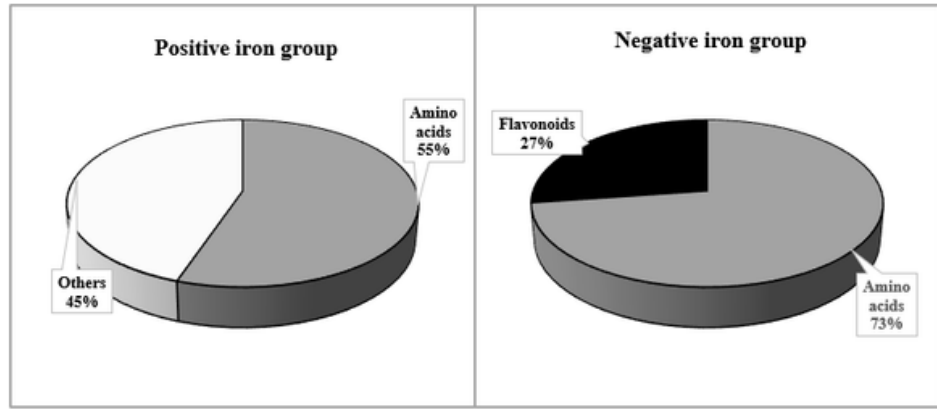

$\square$ Amino acids

Flavonoids

$\square$ Others

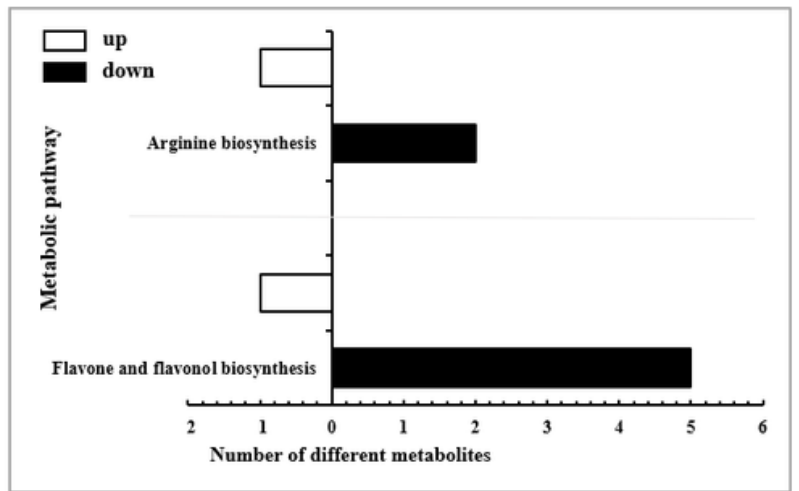

\section{Figure 4}

(a) The volcano graph of differential metabolites. The red origin represents the differential metabolites that are significantly up-regulated in the experimental group, and the green origin represents the significantly down-regulated differential metabolites. Gray dots represent insignificantly differential metabolites. (b) The heat map of differential metabolites. Perform Hierarchical Clustering on the expression of significantly differential metabolites. (c) General overview of significantly differential metabolites in positive ion group and negative ion group. (d) Statistical graph of differential metabolites (Flavone and flavonol biosynthesis and Arginine biosynthesis). 
$\frac{1}{1}$

Arginine biosynthesis

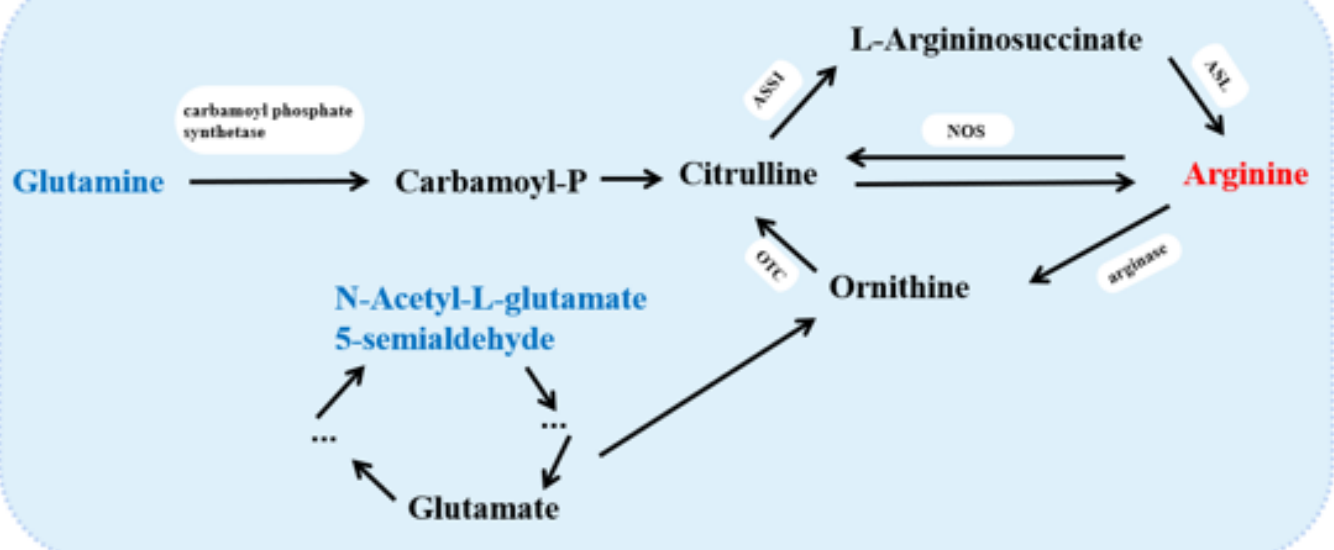

b

\section{Flavone and flavonol biosynthesis}

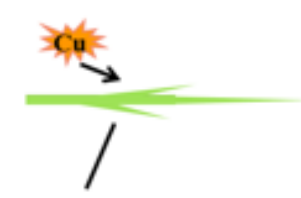

Flavone and flavonol biosynthesis

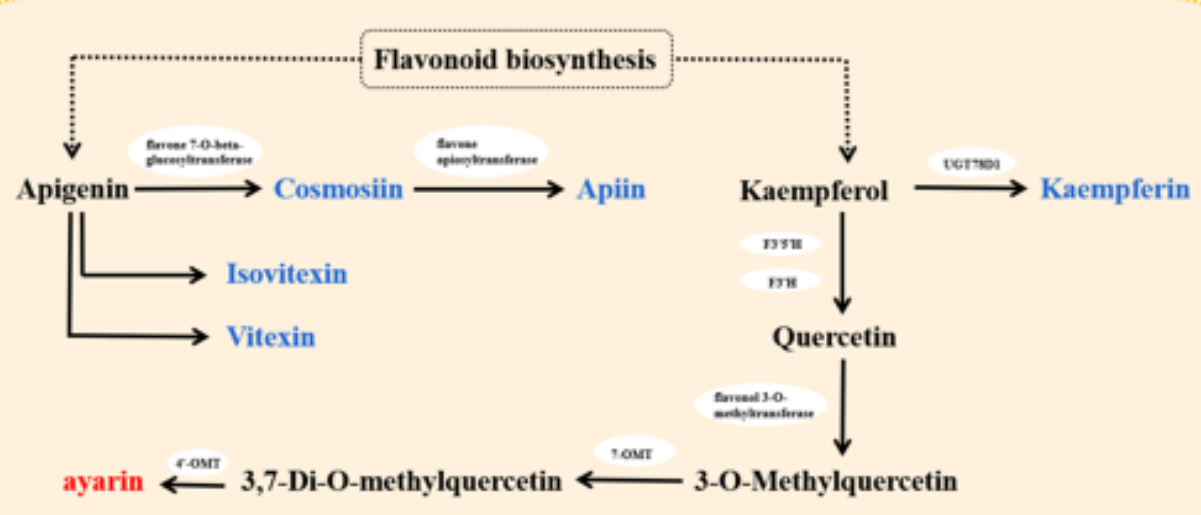

\section{Figure 5}

The variation of differently expressed metabolites in the Ariginine biosynthesis pathway and Flavone and flavonol biosynthesis pathway of P.australis seedlings. The up-regulated were marked with red fonts, down-regulated were marked with blue fonts, insignificant were marked with black fonts and white box indicates enzyme. 